\title{
Системный анализ
}

\section{развития сельских локальных сообществ}

\author{
В. С. Шмаков
}

Институт философии и права СО РАН

Новосибирск, Россия

\section{Аннотация}

Исследуются процессы социально-экономического и социокультурного развития сельских локальных сообществ, выступающих в форме своеобразных моделей, демонстрирующих истинную природу трансформационных процессов в сельскохозяйственных регионах. На основе использования системного анализа определены особенности развития, связи (внутренние и внешние), функции развития сообществ. Выделены механизмы, оказывающие влияние на стабилизацию и устойчивое развитие села: производственно-экономические, социокультурные, институциональные. Сельские локальные сообщества как система обладают структурностью, т. е. имеют внутреннее строение, взаимное расположение элементов (в рамках одного и того же состава элементов возможны те или иные модификации структуры) и являются своеобразной статической моделью системы.

Ключевые слова сельские локальные сообщества, система, элементы, структура, функции, системный анализ

Для цитирования

Шмаков В. С. Системный анализ развития сельских локальных сообществ // Сибирский философский журнал. 2019. Т. 17, № 3. С. 181-193. DOI 10.25205/2541-7517-2019-17-3$181-193$

(c) В. С. Шмаков, 2019 


\section{System Analysis of the Development of Rural Local Communities}

\section{V.S. Shmakov}

Institute of Philosophy and Law SB RAS

Novosibirsk, Russian Federation

Abstract

The article explores the processes of socio-economic and socio-cultural development of rural local communities in the form of specific models that demonstrate the true nature of transformation processes in agricultural regions. Using the system analysis, it establishes the features of development, relations (internal and external) and community development functions. The paper also singles out the mechanisms affecting stabilization and sustainable development of the village: industrial, economic, socio-cultural, and institutional. Rural local communities as a system have a structure, that is, they have an internal composition, the relative position of elements (some modifications of the structure are possible with the same composition of elements) and are a kind of static model of the system.

Keywords

rural local communities, system, elements, structure, functions, system analysis

For citation

Shmakov V. S. System Analysis of the Development of Rural Local Communities. Siberian Journal of Philosophy, 2019, vol. 17, no. 3, p. 181-193. (in Russ.) DOI 10.25205/2541-75172019-17-3-181-193

В процессе трансформации российского сельского хозяйства особое значение приобретают институциональные изменения, связанные с формированием новых форм собственности, становлением многоукладной экономики, реформой аграрной политики государства, эволюцией функционирования человеческого капитала села на новых принципах, выражением которых и выступают складывающиеся отношения собственности и хозяйствования. Меняются количественные и качественные социальноэкономические и социокультурные характеристики сельских локальных сообществ. Кризисные явления, связанные с незавершенностью институциональных преобразований, привели к изменениям в системе жизнеобеспечения, низкому уровню доходов жителей села, разрушению социальной инфраструктуры, ухудшению демографии, деградации человеческого капи- 
тала, оттоку рабочей силы из системы сельского хозяйства страны, нарастанию социально-экономических диспропорций в агропромышленном комплексе (далее - АПК) и появлению депрессивных сельских территорий. Изучение производственно-экономических и социокультурных проблем развития сельских локальных сообществ имеет важное значение для решения широкого круга вопросов. Жители села участвуют в решении многих экономических, социальных, демографических и экологических проблем, осуществляют ряд важнейших социально-экономических и социокультурных функций, сельские территории служат пространственным базисом для размещения производств различных отраслей АПК и других сфер экономики. Необходимо комплексное изучение сельских локальных сообществ на основе актуализации исследований всех компонентов системы АПК. На устойчивое развитие АПК Российской Федерации оказывают существенное влияние несколько обстоятельств. 1. Государственная аграрная политика. 2. Формирование и развитие человеческого капитала. 3. Становление многоукладной экономики. 4. Институциональные изменения. 5. Инновационное развитие села. 6. Развитие аграрной науки, техническое и технологическое обеспечение. 7. Зависимость от природных и климатических факторов. 8. Многофункциональность сельских территорий. 9. Мелкодисперсность сельского расселения. 10. Слабо развитое инфраструктурное хозяйство. 11. Большие проблемы в демографической сфере [Шмаков, 2015].

Недостаточная разработанность проблемы предпосылок и условия устойчивого развития сельских локальных сообществ определяет востребованность анализа развития современного села на основе системной методологии. Необходимо осознать и принимать во внимание, что сельское локальное сообщество выступает как совокупность субъектов, взаимодействующих между собой и с окружающей средой, как система, связанная общей функциональной зависимостью и единой функциональной целью. Как отмечают В. Н. Волкова и А. А. Денисов, потребность в использовании понятия «система» возникает в тех случаях, когда необходимо подчеркнуть, что изучаемое явление представляется достаточно сложным, не пол- 
ностью понятным, при этом целым, единым, и возникает необходимость акцентировать внимание на его упорядоченности, целостности, наличии закономерностей построения, функционирования и развития исследуемого объекта [2014]. Мы полагаем, что системный анализ позволяет сосредоточить внимание на сельских локальных сообществах как именно системе, которая содержит свои особенности развития, свойства и отношения, обладает структурой и функциями. Сельские сообщества как система имеют свойственные им тенденции и условия развития, создают продукцию, формируют человеческий капитал села и т. д., определяют перспективные формы и механизмы их формирования, изменения и функционирования. Выявление стратегических направлений поступательного движения и совершенствования сельских локальных сообществ, анализ их функциональной роли, установление особых принципов организации инновационного развития села, могут содействовать углубленному теоретическому и практическому обеспечению перехода сообществ на путь устойчивого развития, созданию условий для их непрерывного прогрессирования, возможности выбора альтернатив и направлений развития. В перспективе создание методик оценки развития АПК, дающих возможность ранжировать предприятия по уровню их социальной значимости (государственный, региональный, муниципальный), может способствовать созданию мощных территориально-производственных комплексов, территориально-производственных кластеров, позволит разработать модели интегративной оценки становления, формирования и функционирования сельских локальных сообществ, что вполне может служить поддержкой для формирования эффективных механизмов устойчивого развития села.

В качестве объекта нашего исследования мы определяем сельские локальные сообщества, представляемые в виде системы и анализируемые на основе базовых принципов системного анализа. В предметную область исследования мы включаем социально-экономические и социокультурные процессы, происходящие в сельских локальных сообществах, характеризующиеся целым рядом особенностей развития села как системы: понятие, структура, элементы, функции, механизмы. Изучение сельских локальных сообществ в условиях глобализации предполагает выделение трех уровней 
их функционирования: глобальный, региональный и локальный. Село сохраняет свою специфику на локальном уровне, вырабатывая собственные механизмы социально-экономического, социокультурного развития, присущие только им адаптационные реакции к изменяющимся условиям жизни. Сельские локальные сообщества, в своем анагенезе представляются по форме как своеобразные модели, демонстрирующие постоянно меняющуюся сущность трансформационных процессов и роль системного анализа в исследовании сообществ как системы. При этом важны: определение соответствующего сообщества как объекта системного анализа, формулировка понятия, сущности, особенностей, свойств, связей (внутренних и внешних), структуры и функций его развития. Это позволяет более полно представить количественные и качественные характеристики процессов, происходящих в российском селе, выделить систему факторов и показателей эволюции сообществ в условиях модернизации, выявить основные тенденции и перспективы совершенствования АПК, его взаимосвязи с внешней средой, определить механизмы социально-экономического и социокультурного развития сельских локальных сообществ.

Определений понятия «система» в литературе достаточно много, остановимся на наиболее простом и распространенном: система - множество связанных между собой элементов, рассматриваемых как целое, относительно независимое от окружающей среды, явление. Системный анализ является научно-методологической дисциплиной и представляет комплекс научных методов, принципов и средств исследований сложных систем в совокупности и связи всех его элементов, определяющий этапы проведения исследований [Мишенин, 2001; Голубков, 2009; Батоврин, 2012; Мыльник и др., 2013]. В основе методологии системного анализа лежат три концепции: описание системы, выявление проблемы, выбор и реализация направления ее решения. С этой точки зрения системная методология представляет собой наиболее упорядоченную основу для анализа таких сложных открытых систем, как сельские локальные сообщества, установления их основных компонентов, сфер деятельности, структуры и функций. 
Одной из наиболее важных особенностей применения системного анализа представляется необходимость соблюдения гармонии, применяемых формализованных и неформализованных средств и методов исследования. Это достаточно сложно. Так, например, методики Э. Квейда [1969] и С. Оптнера [1969] предлагают больше внимания уделять проблеме разработки и исследования альтернатив принятия решений. В.Г. Афанасьев, прослеживая функциональную зависимость между компонентами исследуемой системы, в первую очередь выделяет ее внутренние связи (между компонентами и системой в целом), внешние связи (между системой в целом и другой системой, чьим компонентом она является) [2018]. В литературе глубоко и всесторонне исследуются положения о том, что такое система, каковы ее состав, структура, функции. Большое место отводится изучению взаимодействия общественных систем с окружающей природной и социальной средой, становлению, совершенствованию и развитию систем. Если говорить в целом, то функциональный анализ сводится к определению различных видов функциональных зависимостей, обнаруживающих и раскрывающих основную суть исследуемой системы.

Выделим основные особенности, характеризующие сельские локальные сообщества как систему.

Целостность. Сельские сообщества состоят из отдельных, связанных между собой, сформировавшихся в процессе эволюции, элементов, представляющих определенное единство, имеющих особенности строения, обособленную позицию, структуру, функции и обладающие относительной независимостью от внешней среды, что определяет их как самостоятельную систему.

Иерархичность. Сельские локальные сообщества по мере своего развития формируют достаточно сложное образование, состоящее из целого и элементов (чаще всего сельское сообщество замыкается на одном или нескольких предприятиях, обеспечивающих население рабочими местами и образующие совокупность связей, сочетающих все элементы сообщества в определенную целостность; эти элементы представляют собой подсистемы) и обеспечивающее единство ее развития и функционирования. Все 
элементы системы, как ее части, обладают определенными свойствами и некоторой самостоятельностью и имеют связи с другими подсистемами. Локальные сообщества, являясь сложной системой (число подсистем которой достаточно велико, а состав разнороден), имеют границы, разделяющие их между собой и отделяющие их от внешней среды. Они могут являться достаточно незамкнутыми, допускающими взаимовлияние, внешние воздействия, что обеспечивает оптимальное приспособление к окружению и успешное развитие во времени. Вся система должна находиться в состоянии внутреннего и внешнего равновесия.

Сообщества обладают определенной автономностью, самоуправляемостью, адаптивностью, т. е. способностью реагировать на изменение условий жизни, приспосабливаться к ним наилучшим для себя способом и достигать цели по поддержанию основных характеристик своего функционирования на необходимом уровне, обладать способностью к самовоспроизводству и саморазвитию.

Сообщества как системы обладают структурностью, т. е. имеют определенное внутреннее строение, взаимное расположение элементов и включают совокупность связей между элементами системы. Прослеживается зависимость свойств одного элемента от свойств другого, что обеспечивает целостность и возможность регулирования развития и функционирования систем в целях достижения поставленных задач. Структура является своеобразной статической составляющей системы, включающей ее внутренние строения и связи. Связи разделяют по ряду признаков: управление (горизонтальные и вертикальные, прямые и обратные, внешние и внутренние и др.); по характеру взаимодействия элементов (слабые и сильные, жесткие и гибкие). Всё, что не входит в систему, принадлежит внешней среде. Систему и ее внешнюю среду разделяет граница. Внешняя среда - совокупность естественных и искусственных систем, которые оказывают действие на сообщества. Сельские локальные сообщества как всякая система характеризуются наличием своих особенностей, свойств, обладают определенной структурой и функциями. Соответственно, их целостная деятельность является результатом взаимодействия всех структурных составляющих, 
определяющих функционирование ее отдельных уровней, подсистем и элементов, позволяющих осуществлять передачу информации, ставить цели, выполнять функции управления, устанавливать связи и отношения с внешней средой и пр. Необходимо подчеркнуть, что целостное функционирование является результатом взаимодействия всех ее уровней, подсистем и элементов. Как справедливо отмечает К. Н. Лебедев, для многих сложных социальных систем характерно наличие разных по уровню, иногда не коррелирующих между собой целей [2008]. И здесь важное место занимает «функция» системы, представляющая способы, средства и методы ее взаимодействия с внешней и внутренней средой, и выражающая поведение системы как упорядоченной, закономерной и организованной структуры, приводящей к достижению поставленных целей. Функция системы - это проявление свойств, качеств системы во взаимодействии с другими объектами системного и несистемного порядка, своеобразное выражение определенной относительно устойчивой реакции системы на изменение ее внутреннего состояния и ее внешней среды. Функции системы как целого определяют функции, которые выполняет в системе каждый из ее компонентов. Наличие функций системы определяется существованием внешней и внутренней среды. Внутренние функции системы создают условия для существования, развития и регулирования элементов, взаимосвязей внутри системы. Это способ взаимодействия частей внутри целого. К внутренним можно отнести функцию целеполагания, определяющую цели и задачи развития сообществ; распорядительную, регулирующую действия органов управления; координационную, благодаря которой происходит налаживание совместных действий элементов; учета и контроля (проверка соответствия производимых действий принятым нормам и законам); оценочную, регулирующую поведение элементов системы внутри и по отношению к внешней среде, что требует постоянной координации и корректировки элементов, взаимосвязей между ними. Внешние функции системы регулируют отношения с внешней средой, включая задействование и использование ее вещественных, энергетических, информационных и др. ресурсов. Их количество достаточно велико, но многие из них имеют индивидуальную неповторимость и являются для 
данной системы наиболее важными. Выделим их касательно собственно сельских локальных сообществ. Потребительские функции - получение из внешней среды сырья, материалов, технологий, энергии, информации и т. д., которые обеспечивают существование и развитие системы. Обслуживающие функции - связь с системами как более высокого, так и более низкого уровня. Любая система занимает определенное место в иерархии внешних систем, и необходимы иерархические взаимосвязи. Адаптивные функции особенно характерны для развития сельских локальных сообществ, очень часто вынужденных приспосабливаться к меняющимся, часто не по их воле, условиям. Они реализуются в виде сотрудничества системы с ее окружением, взаимного изменения поведения и пр. Функции поглощения - взаимодействие в процессе экспансии внешней среды и других систем. Эта позиция характеризует систему как активное либо пассивное образование, находящееся в состоянии интерактивности со средой, поглощающее либо отдающее часть элементов, ресурсов, связей и свойств. Наконец, функция согласования позволяет регулировать отношения внутри системы и с внешними системами в процессе своей реализации как целого. По большому счету, все эти функции исполняют роль активатора и регулятора системы, в ходе внутренних и внешних взаимодействий, проявляя свойства системы. Функции сельских локальных сообществ как системы определяют основные тенденции и механизмы социально-экономического и социокультурного развития села. Выделим наиболее важные механизмы, оказывающие организующее влияние на устойчивое инновационное развитие сельских локальных сообществ. Их можно объединить в три основные группы: производственно-экономические, социокультурные и институциональные. В той или иной степени они ориентированы на эффективные инструменты формирования инновационного потенциала сельскохозяйственных регионов, на обеспечение социально ориентированного развития сельских сообществ и АПК.

1. Производственно-экономические механизмы определяют комплексное развитие сельского хозяйства, в их рамках решаются вопросы обновления и совершенствования или же, напротив, деградации сельских 
локальных сообществ. Если осуществляется процесс их совершенствования, то разрабатываются стратегия, программы и инструментарий инновационного развития АПК, осуществляется мониторинг развертывания и функционирования системы комплекса, эффективности его работы.

2. В ситуации совершенствования сельских локальных сообществ, разработка социокультурных индикаторов их развития способствует созданию механизмов становления социального благополучия населения, отражающих устойчивое развитие, уровень и качество жизни жителей, формирование и поддержание инфраструктуры, обеспечивающих эволюцию их человеческого капитала.

3. Систематизация и классификация институциональных факторов и условий, определяющих устойчивое развитие и направленных на создание эффективных экономических, политических и социокультурных институтов, определяющих сферу социально-экономической и социокультурной деятельности, оказывают определяющее влияние на формирование системы институциональной среды, служат стимулятором задействования факторов улучшения жизни сельских локальных сообществ, обеспечивающих инновационность и устойчивость их развития. Например, развитие кластерной системы ведения сельского хозяйства, ориентированного на применение новых технологий и новой техники, полную переработку сырья, может в значительной степени повысить производительность труда и увеличить выход конечного продукта, а в итоге будет способствовать улучшению качества жизни жителей села, переходу сельских локальных сообществ на социально ориентированное развитие.

Итак, функциональный анализ жизнедеятельности сельских локальных сообществ сводится в первую очередь к определению различных видов функциональных зависимостей, обнаруживающих и раскрывающих суть исследуемой системы как совокупности связанных и взаимодействующих между собой элементов, образующих некую структуру, исполняющую определенные функции. Сельские локальные сообщества включают в себя несколько подсистем: экономико-производственную, социокультурную, технологическую, экологическую (природоохранную), определяющих их особенности, структуру и функции. Как вполне самостоятельные подсис- 
темы они имеют тоже структурированные составляющие: территория расселения сельских локальных сообществ; производственные, организационные, социально-политические и культурологические структуры; экологические и природоохранные. Отличаются рядом особенностей, характеризующих именно данную подсистему: зависимость от природноклиматических условий ведения хозяйства; сезонность сельской экономики; низкое плодородие земель; мелкодисперсность сельского расселения; многофункциональность сельских территорий; слабая инфраструктурная обустроенность; специфика демографии сельских сообществ; интересы, ценностные ориентации и потребности входящих в них индивидов; образ и стиль их жизни, связанные с этосом крестьянства.

На основе проведенного анализа можно сделать вывод о том, что сельское локальное сообщество обладает всеми признаками саморазвивающейся системы, является источником ряда незаменимых общественных благ, выполняет множество важнейших функций: производственно-экономическую, социокультурную, демографическую, экологическую, рекреационную (контроль над территориями) и ряд других. Для обеспечения устойчивого производственно-экономического и социокультурного развития сельских локальных сообществ требуется создание социально-экономического механизма системного развития, на основе которого возможно решение глобальных задач, стоящих перед сельскими локальными сообществами, включая широкомасштабное развитие аграрного сектора, определяемое спецификой интересов субъектов сельского хозяйства и их противоречиями, с использованием всех имеющихся ресурсов (природных, климатических, человеческих, экологических, ландшафтных и др.), а также внимание к наиболее отсталыми сельскими регионам (каких у нас большинство).

\section{Список литературы / References}

Афанасьев В. Г. Системность и общество. М., 2018.

Afanasiev V. G. Sistemnost i obshchestvo [System and society]. Moscow, 2018. (in Russ.) 
Батоврин В. К. Толковый словарь по системной и программной инженерии. М., 2012.

Batovrin V. K. Tolkovyi slovar po sistemnoi i programmnoi inzhenerii [Explanatory dictionary of system and software engineering]. Moscow, 2012. (in Russ.)

Волкова В. Н., Денисов А. А. Теория систем и системный анализ. М., 2014.

Volkova V. N., Denisov A. A. Teoriya sistemis i sistemnyi analiz [System theory and system analysis]. Moscow, 2014. (in Russ.)

Голубков Е. П. Методы системного анализа при принятии управленческих решений. М., 2009.

Golubkov E. P. Metody sistemnogo analiza pri prinyatii upravlencheskikh reshenii [Methods of system analysis in management decision-making]. Moscow, 2009. (in Russ.)

Квейд Э. Анализ сложных систем. М., 1969.

Quaid E. Analiz slozhnykh system [Analysis of complex systems]. Moscow, 1969. (in Russ.)

Лебедев К. Н. Системный подход и методология менеджмента. М., 2008.

Lebedev K. N. Sistemnyi podhod i metodologiya menedzhmenta [System approach and management methodology]. Moscow, 2008. (in Russ.)

Мишенин А. И. Теория экономических информационных систем. М., 2001. Mishenin A. I. Teoriya ehkonomicheskikh Informacionnykh system [Theory of economic information systems]. Moscow, 2001. (in Russ.)

Мыльник В. В., Титаренко В. В., Волочиенко В. А. Исследование систем управления. М., 2013.

Mylnik V. V., Titarenko V. V., Volochienko V. A. Issledovanie system upravleniya [The study of control systems]. Moscow, 2013. (in Russ.)

Оптнер С. Л. Системный анализ для решения деловых и промышленных проблем. М., 1969.

Optner S. L. Sistemnyi analiz dlya resheniya delovykh i promyshlennykh problem [System analysis to solve business and industrial problems]. Moscow, 1969. (in Russ.) 
Шмаков В. С. Инновационный потенциал развития российского села // Сибирский философский журнал. 2017. Т. 15, № 2. С. 101-111.

Shmakov V. S. Innovatsionnyi potentsial razvitiya rossiiskogo sela [Innovative potential of Russian rural development]. Siberian Journal of Philosophy, 2017, vol. 15, no. 2, p. 101-111. (in Russ.)

Материал поступил в редколлегию

Received

10.03.2019

\section{Сведения об авторе / Information about the Author}

Шмаков Владимир Сергеевич, доктор философских наук, ведущий научный сотрудник Института философии и права СО РАН (ул. Николаева, 8, Новосибирск, 630090, Россия)

Vladimir S. Shmakov, Doctor of Science (Philosophy), Leading researcher Institute of Philosophy and Law SB RAS (8 Nikolaev Str., Novosibirsk, 630090, Russian Federation)

vsshmakov@gmail.com 